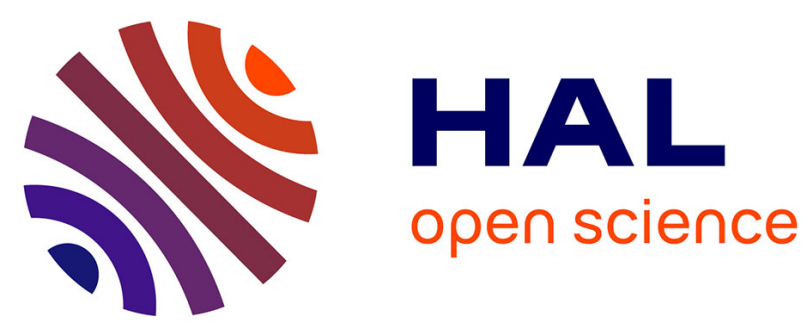

\title{
Should we fear tubing adsorption of antibacterial drugs in extracorporeal membrane oxygenation? An answer for cephalosporins and carbapenems
}

Camille Tron, Cyril Leven, Pierre Fillâtre, Nicolas Maillard, Nicolas Nesseler, Pierre Tattevin, Erwan Flécher, Eric Bellissant, Marie-Clémence Verdier, Florian Lemaitre

\section{To cite this version:}

Camille Tron, Cyril Leven, Pierre Fillâtre, Nicolas Maillard, Nicolas Nesseler, et al.. Should we fear tubing adsorption of antibacterial drugs in extracorporeal membrane oxygenation? An answer for cephalosporins and carbapenems. Clinical and Experimental Pharmacology and Physiology, 2016, 43 (2), pp.281-283. 10.1111/1440-1681.12527 . hal-01255854

\section{HAL Id: hal-01255854}

\section{https://hal-univ-rennes1.archives-ouvertes.fr/hal-01255854}

Submitted on 8 Feb 2016

HAL is a multi-disciplinary open access archive for the deposit and dissemination of scientific research documents, whether they are published or not. The documents may come from teaching and research institutions in France or abroad, or from public or private research centers.
L'archive ouverte pluridisciplinaire HAL, est destinée au dépôt et à la diffusion de documents scientifiques de niveau recherche, publiés ou non, émanant des établissements d'enseignement et de recherche français ou étrangers, des laboratoires publics ou privés. 


\section{Should we fear tubing adsorption of antibacterial drugs in extracorporeal membrane oxygenation? An answer for cephalosporins and carbapenems}

Camille Tron ${ }^{1,2}$, Cyril Leven ${ }^{1,2}$, Pierre Fillâtre ${ }^{3}$, Nicolas Maillard ${ }^{4}$, Nicolas Nesseler ${ }^{5}$, Pierre Tattevin $^{3,7}$, Erwan Flecher ${ }^{6,8}$, Eric Bellissant ${ }^{1,2,7}$, Marie-Clémence Verdier ${ }^{1,2,7}$ and Florian Lemaitre ${ }^{1,}$ 2,7

1 Rennes University Hospital, Department of Clinical and Biological Pharmacology and Pharmacovigilance, Pharmacoepidemiology and Drug Information Centre, Rennes, France.

${ }^{2}$ Rennes 1 University, Faculty of Medicine, Laboratory of Experimental and Clinical Pharmacology, Rennes, France.

${ }^{3}$ Infectious Diseases and Intensive Care Unit, Rennes University Hospital, Rennes, France.

${ }^{4}$ Pharmacy department, Rennes University Hospital, Rennes, France.

${ }^{5}$ Surgical Intensive Care Unit Department, Rennes University Hospital, Rennes, France.

${ }^{6}$ Thoracic and Cardio-Vascular Surgery Department, Rennes University Hospital, Rennes, France.

${ }^{7}$ Inserm, CIC-P 1414 Clinical Investigation Centre, Rennes, France.

${ }^{8}$ Inserm 1099, CIC-IT, Clinical Investigation Centre, Rennes, France.

\section{Corresponding author:}

Camille TRON, Hôpital Pontchaillou, CHU de Rennes, Service de Pharmacologie, 35033 Rennes cedex, France

Mail: tron.camille@gmail.com ; tel: 0033.2.99.28.42.80 ; fax: 0033.2.99.28.41.84 


\section{Conflict of interest statement:}

The authors have no conflict of interest to declare.

Short title: «Adsorption of antibacterial drugs in ECMO circuit »

\section{ABSTRACT}

Extracorporeal membrane oxygenation (ECMO) procedure used in the management of patients with cardiac and/or respiratory failure could modify drugs pharmacokinetics (PK) properties. Studying the impact of ECMO devices on drugs PK is warranted to optimize dosage and ensure clinical outcomes. We aimed to characterize the behavior of four cephalosporins and three carbapenems commonly used in an ECMO circuit with an in-vitro approach focusing on the coated tubing, support of the extracorporeal circulation. Results suggest that these antibiotics are not sequestrated by ECMO tubing. This pilot mechanistic study provides original data that will contribute to improve our understanding of the impact of ECMO on the PK of drugs commonly used in intensive care unit patients.

Keywords: Extracorporeal membrane oxygenation; pharmacokinetics; adsorption; antibiotics; intensive care.

Extracorporeal membrane oxygenation $(\mathrm{ECMO})$ is a supportive care used in the management of patients with life-threatening cardiac and/or respiratory failure. The use of ECMO in the management of cardiopulmonary disease is increasing. Since its first application in the 70's, performances of the technology and devices have been dramatically improved, leading to safer and more effective system (1). Hence, indications of ECMO have expanded, and are also becoming better defined, although data from clinical trials are needed in order to build thorough practice guidelines $(1,2)$. In addition to clinical aspects, potential impact of ECMO on the pharmacokinetics (PK) of drugs used in these patients must be considered to improve the therapeutic strategy. The alterations in PK parameters described in the critically ill population eligible for ECMO therapy may induce additional PK variability (3). Although clinical data are sparse, recent studies suggested that ECMO circuit itself is responsible for PK alterations which could increase the risk of therapeutic failure or toxicity (3-7). Sequestration of drugs in ECMO circuits has been proposed as an explanation for the low concentrations observed in clinical practice $(4,8)$. Thus, studies on the impact of ECMO devices on drug PK are warranted to 
optimize dosage and ensure treatment efficacy. During antibacterial treatment, the early achievement of drugs concentrations within the therapeutic target is associated with improved outcome. More specifically, for betalactam agents, maintaining drug concentrations above the minimal inhibitory concentration of the drug on the bacteria targeted is crucial to ensure treatment success (9). Among the factors potentially associated with subtherapeutic levels of betalactam agents, ECMO is a major cause of concern, as this intervention applies to the sickest patients, for whom sub-optimal use of drugs will be life-threatening (10).

We aimed to characterize the behavior of antibiotics (ATB) commonly used in these patients (betalactam agents), in an ECMO circuit with an in-vitro approach focusing on the coated tubing support of the extracorporeal circulation.

Cephalosporins (CS: cefotaxime, ceftriaxone, ceftazidime, cefepime) and carbapenems (CP: imipenem, meropenem, ertapenem) were bought from local drug purchases companies and prepared following label instructions for clinical use in humans. Drug-free human whole blood obtained from the Etablissement Français du Sang (Rennes, France) was spiked with ATB to reach concentrations closed to the peak concentration of each drug. Blood samples were disposed in PVC Bioline ${ }^{\circledR}$ coated tubing (Maquet, Germany) from an ECMO device system (experimental conditions), or inert glass tubes (control conditions). Samples were incubated at $37^{\circ} \mathrm{C}$ under agitation to mimic real conditions. Plasma concentrations of the drugs were assessed just before and after 5, 15, 30, 60, 120 and 240 minutes of incubation for experimental and control groups. This design aimed to detect a potential sequestration of drugs by the device. The whole experiments were replicated five times. Cephalosporin concentrations were measured using high performance liquid chromatography (HPLC) associated with UV-spectrometry detection and according to the validated method reported by Verdier et al. (11). The method used to quantify carbapenems was adapted from (12). Briefly, analytes were extracted from plasma using protein precipitation with acetonitrile followed by a liquid-liquid extraction with dichloromethane. Extracts were analyzed by HPLC tandem mass spectrometry. 
Changes in mean remaining drug concentrations over time were compared between control and experimental conditions by modeling using a linear mixed effect model as previously done in some similar studies $(5,13)$. The mixed effect model was then fitted with $\mathrm{R}$ software version 3.0.2 and the "nlme" library (14).

No significant differences in remaining concentrations in tubing or controls were observed for CS and $\mathrm{CP}$. This suggests that $\mathrm{CS}$ and $\mathrm{CP}$ are not sequestrated by ECMO tubing (Figure 1). After 4 hours of incubation at $37^{\circ} \mathrm{C}$, the decrease in drug concentrations was significant (>15\%) for imipenem, cefepime and cefotaxime, but with the same extent in the controls and the experimental conditions, and thus can be ascribed to sub-optimal drug stability of most betalactam agents.

These results show that PK changes in ECMO patients treated with CS or CP might not be due to tubing sequestration. It was suspected, on the ground that betalactam are hydrophilic drugs. Indeed, Wildschut et al., reported a correlation between octanol/water partition coefficient ( $\log \mathrm{P})$ of a drug and its clearance during ex-vivo procedure conducted with neonatal circuits. These authors have showed that drug loss in ECMO circuit is lower for hydrophilic drugs such as betalactam (7). A lack of effect of ECMO on the PK of hydrophilic drugs has also been highlighted in patients, particularly with the antiviral oseltamivir (6). On the opposite, Shekar et al. have reported a substantially higher clearance of meropenem, a CP drug, during ex-vivo experiments and in adult patients treated with ECMO $(4,10)$. In a larger case-control study, no difference was found in meropenem PK between ECMO patients and non-ECMO patients (15). In view of these conflicting results, experimental study like the present one appears useful to understand underlying mechanisms which make ECMO device a factor of PK modifications. Thus, PK alterations of hydrophilic drugs might be more likely due to hemodilution mechanism associated with the additional compartment represented by the circuit or high volume of fluid supplementation requested in intensive care patients. Nevertheless, $\log \mathrm{P}$ value of a drug is not the only parameter determining the drug disposition in an ECMO circuit. Shekar et al. have demonstrated in an ex-vivo study that as lipophilicity, degree of protein binding may be involved as well (13). In the present work we did not observed any influence of this factor since drugs studied have disparate levels of protein binding (respectively $70 \%, 2 \%, 95 \%, 30 \%, 90 \%, 10 \%, 19 \%$ for imipenem, meropenem, ertapenem, cefotaxime, ceftriaxone, ceftazidime, cefepime) but the same profile of drug recovery in the circuit compared to the control group (no significant difference). 
However, Other source of PK alteration during ECMO procedure could not be excluded. Drug adsorption on the circuit may also depend on circuit duration of use, since binding sites may become saturated after a few hours of operation (16). Besides, it would be worth to perform further experiments focusing on the other components of the system which may be involved in drug sequestration, in particular the membrane oxygenator. It is admitted that in-vitro studies have limitations and working with animal model could be considered. Such an approach has been proposed by Shekar et al. (17) but to date no results has been published. However, animal model request special environment and expertise making this kind of studies hard to implement.

Thus, this pilot mechanistic study provides original data that will contribute to improve our understanding of the impact of ECMO on the PK of drugs commonly used intensive care patients. CS and $\mathrm{CP}$ drug sequestration on ECMO tubing seems unlikely but other causes of drug loss within circuit have not been ruled out. Complementary in-vitro, ex-vivo and patient studies should be planned to completely explore the PK of betalactam antibiotics during ECMO. This is the next step of a translational project ongoing in our center. It includes in-vitro data presented here, ex-vivo approach and an in-vivo study with ICU patients. This should allow having a complete view on sequestration of drugs by tubing, other components of the ECMO-circuit as well as the effect of patient's condition on drug pharmacokinetics.

\section{Legend:}

Figure1: Percentage of remaining concentration of cephalosporins and carbapenems according to time of incubation, (mean $+/-$ standard deviation, $n=5$ ). No significant differences were observed between experimental and control conditions. (A) Imipenem: $p=0.38$, (B) Meropenem: $p=0.50,(C)$ Ertapenem: $p=0.84,(D)$ Cefotaxime: $p=0.62$, (E) Ceftriaxone: $p=0.09,(F)$ Ceftazidime: $p=0.35,(G)$ Cefepime: $p=0.27$ 


\section{References}

1. Abrams D, Combes A, Brodie D. Extracorporeal membrane oxygenation in cardiopulmonary disease in adults. J Am Coll Cardiol. 2014 Jul;63(25 Pt A):2769-78.

2. Shekar K, Mullany D V., Thomson B, Ziegenfuss M, Platts DG, Fraser JF. Extracorporeal life support devices and strategies for management of acute cardiorespiratory failure in adult patients: a comprehensive review. Crit Care. 2014;18(3):219.

3. Shekar K, Fraser JF, Smith MT, Roberts JA. Pharmacokinetic changes in patients receiving extracorporeal membrane oxygenation. J Crit Care. 2012 Dec;27(6):741.e9-18.

4. Shekar K, Roberts JA, Mcdonald Cl, Fisquet S, Barnett AG, Mullany D V., et al. Sequestration of drugs in the circuit may lead to therapeutic failure during extracorporeal membrane oxygenation. Crit Care. 2012;16(5):R194.

5. Lemaitre F, Hasni N, Leprince P, Corvol E, Belhabib G, Fillâtre P, et al. Propofol, midazolam, vancomycin and cyclosporine therapeutic drug monitoring in extracorporeal membrane oxygenation circuits primed with whole human blood. Crit Care. 2015 Feb;19(1):40.

6. Lemaitre F, Luyt C-E, Roullet-Renoleau F, Nieszkowska A, Zahr N, Corvol E, et al. Impact of extracorporeal membrane oxygenation and continuous venovenous hemodiafiltration on the pharmacokinetics of oseltamivir carboxylate in critically ill patients with pandemic (H1N1) influenza. Ther Drug Monit. 2012 Apr;34(2):171-5.

7. Wildschut ED, Ahsman MJ, Allegaert K, Mathot R a. A, Tibboel D. Determinants of drug absorption in different ECMO circuits. Intensive Care Med. 2010 Dec;36(12):2109-16.

8. Mehta NM, Halwick DR, Dodson BL, Thompson JE, Arnold JH. Potential drug sequestration during extracorporeal membrane oxygenation: results from an ex vivo experiment. Intensive Care Med. 2007 Apr;33(6):1018-24.

9. Waele JJ De, Lipman J, Akova M, Bassetti M, Dimopoulos G, Kaukonen M, et al. Risk factors for target non-attainment during empirical treatment with $\beta$-lactam antibiotics in critically ill patients. Intensive Care Med. 2014 Jul;40(9):1340-51.

10. Shekar K, Roberts JA, Ghassabian S, Mullany D V., Wallis SC, Smith MT, et al. Altered antibiotic pharmacokinetics during extracorporeal membrane oxygenation: cause for concern? J Antimicrob Chemother. 2013 Mar;68(3):726-7. 
11. Verdier M-C, Tribut O, Tattevin P, Le Tulzo Y, Michelet C, Bentue-Ferrer D. Simultaneous Determination of $12 \beta$-Lactam Antibiotics in Human Plasma by High-Performance Liquid Chromatography with UV Detection: Application to Therapeutic Drug Monitoring. Antimicrob Agents Chemother. 2011 Jul 25;55(10):4873-9.

12. van Rijn SP, Wessels AMA, Greijdanus B, Touw DJ, Alffenaar JWC. Quantification and validation of ertapenem using a liquid chromatography-tandem mass spectrometry method. Antimicrob Agents Chemother. 2014 Jun 1;58(6):3481-4.

13. Shekar K, Roberts $\mathrm{J}$ a, Mcdonald Cl, Ghassabian S, Anstey C, Wallis SC, et al. Protein bound drugs are prone to sequestration in the extracorporeal membrane oxygenation circuit: results from an ex vivo study. Crit Care; 2015;19(1):1-8.

14. The R Project for Statistical Computing. http://www.r-project.org/.

15. Donadello K, Antonucci E, Cristallini S, Roberts JA, Beumier M, Scolletta S, et al. $\beta$-Lactam pharmacokinetics during extracorporeal membrane oxygenation therapy: A case-control study. Int J Antimicrob Agents. Elsevier; 2015 Mar 3;45(3):278-82.

16. Dagan O, Klein J, Gruenwald C, Bohn D, Barker G, Koren G. Preliminary studies of the effects of extracorporeal membrane oxygenator on the disposition of common pediatric drugs. Ther Drug Monit. 1993 Aug;15(4):263-6.

17. Shekar K, Roberts JA, Smith MT, Fung YL, Fraser JF. The ECMO PK Project: an incremental research approach to advance understanding of the pharmacokinetic alterations and improve patient outcomes during extracorporeal membrane oxygenation. BMC Anesthesiol. 2013 Jan;13(1):7. 

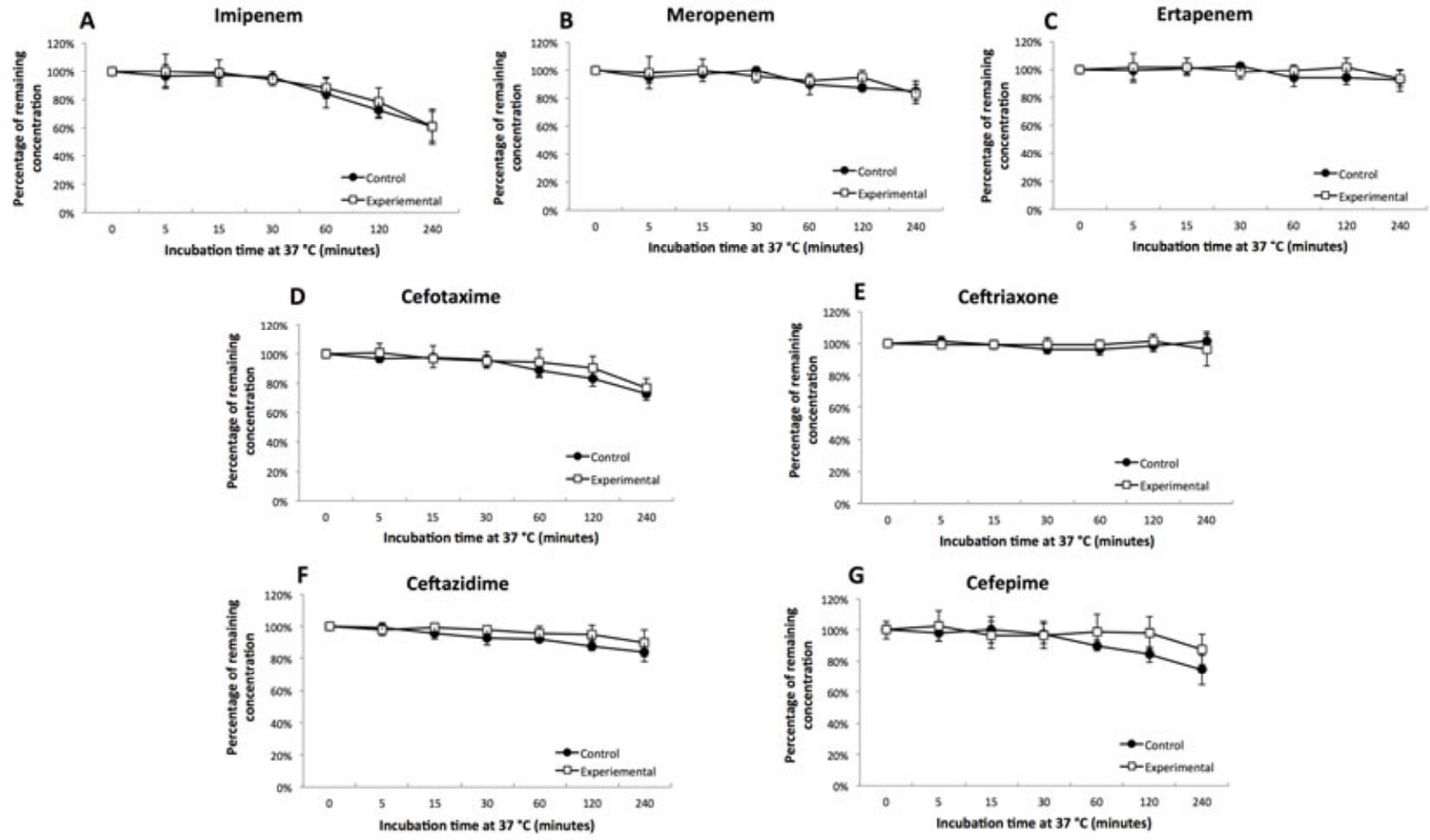